\title{
Artificial neural networks application for solid fuel slagging intensity predictions
}

\author{
Stawomir Kakietek ${ }^{1, *}$, Jerzy Szymczak $^{1}$ \\ ${ }^{1}$ Instytut Energetyki Zakład Procesów Cieplnych, Augustówka 36 St.,02-981 Warsaw, Poland
}

\begin{abstract}
Slagging issues present in pulverized steam boilers very often lead to heat transfer problems, corrosion and not planned outages of boilers which increase the cost of energy production and decrease the efficiency of energy production. Slagging especially occurs in regions with reductive atmospheres which nowadays are very common due to very strict limitations in $\mathrm{NO}_{\mathrm{x}}$ emissions. Moreover alternative fuels like biomass which are also used in combustion systems from two decades in order to decrease $\mathrm{CO}_{2}$ emissions also usually increase the risk of slagging. Thus the prediction of slagging properties of fuels is not the minor issue which can be neglected before purchasing or mixing of fuels. This however is rather difficult to estimate and even commonly known standard laboratory methods like fusion temperature determination or special indexers calculated on the basis of proximate and ultimate analyses, very often have no reasonable correlation to real boiler fuel behaviour. In this paper the method of determination of slagging properties of solid fuels based on laboratory investigation and artificial neural networks were presented. A fuel data base with over 40 fuels was created. Neural networks simulations were carried out in order to predict the beginning temperature and intensity of slagging. Reasonable results were obtained for some of tested neural networks, especially for hybrid feedforward networks with PCA technique. Consequently neural network model will be used in Common Intelligent Boiler Operation Platform (CIBOP) being elaborated within CERUBIS research project for two BP-1150 and BB-1150 steam boilers. The model among others enables proper fuel selection in order to minimize slagging risk.
\end{abstract}

\section{Introduction}

Slagging and fouling issues are a headache of boiler operators, especially from last two decades when alternative fuels became more and more important and $\mathrm{NO}_{\mathrm{x}}$ emissions limitations left an imprint on combustion low excess air strategy. Fouling phenomena is more or less solved by ash blowers (steam, acoustic) located in the second part of the boiler which usually removes deposits from tubes. However in case of slagging in the combustion chamber and first plate heaters removing the deposit is more complicated and sometimes

\footnotetext{
* Corresponding author: slawomir.kakietek@ien.com.pl
} 
almost impossible. Thus avoiding the slagging is rather the proper direction to deal with this phenomena.

The mechanism of slagging is very complex. Several main factors influence slagging like: amount and chemical composition of ash, physical properties of ash particles, distribution of mineral matter in coal particles and the mechanism of ash forming, temperature and excess air level in combustion chamber and aerodynamic as well. Due to such complex phenomena a number of methods of slagging intensity predictions were created as: determination of ash fusibility temperatures, slagging indexers by Rundygin [1] determined on the basis of ash analysis or Żelkowski [2] determined by laboratory investigations in small scale, pilot scale experiments [3] or more detailed experiments based on SEM or QEMSCNAN [4,5] or even real scale measurements. However whilst ash fusion temperatures for the same fuel samples can differ up to $300 \mathrm{C} \mathrm{deg}$. depending on which laboratory they were investigated [4], the indexers are very often based on specific group of fuels and additionally they are determined on the basis of ash derived in laboratory conditions not from the pulverized flame, laboratory methods do not reflect all important aspects of pulverized flame in the boiler, even real scale measurements are limited due to e.g. number of fuels or conditions which can be investigated in real conditions. More detailed, advanced experiments (e.g. SEM) seems to be more reliable than others and rather on that basis advanced numerical CFD models of slagging should be developed [6]. Nevertheless they are more expensive and time consuming then others. These factors undermine their usability in real applications unfortunately.

Even laboratory scale experiments do not reflect all conditions in the boiler, relatively good results can be obtained in case of small scale comparative laboratory measurements where however pulverized flame is investigated. In such methods intensity of slagging is determined first for base fuel (currently utilized in the boiler) and secondly for other fuels or their blends which are supposed to be used in the boiler. This approach however has also limiting factors like: time, significant amount of fuel samples and costs. The solution of these issues may lay in smart connection of comparative laboratory investigations and artificial neural networks (ANN).

ANN were successfully utilized in slagging related issues [7-12]. These so-called "blackbox model", in spite of lack of model transparency and elegance, were able to extract information from highly complex, non-linear and sometimes ill-defined issues, provided that a representative set of data is available. Most of presented applications of ANN in slagging phenomena were based on typical multilayer feedforward neural network (MFNN) and on available, selected data from either laboratory set of experiments or particular boiler. The issue arises where limited training data for ANN is available. Moreover these available data "describes" several areas of slagging phenomena like slagging of hard coals, lignite coals, their mixtures and raw or torrefied biomass or refused-derived fuels (RDF). In such spectrum of fuels with limited training data typically used MFNN may be useless.

In this paper, the authors explored the potential use of principal component analysis (PCA) technique connected with MFNN and statistical analysis to predict the slagging intensity defined by two indexers obtained from laboratory scale experiments based on limited available data. The inputs to ANN were defined as technical analysis of fuel (moisture, ash and volatiles content, and calorific value) and ash mineral analysis (eleven compounds). Levenberg-Marquardt training algorithm was used in order to optimize the training process. Finally PCA hybrid neural network was tested against not seen data and sensitivity analysis was performed to determine the most critical factors for network performance. 


\section{Experimental data}

Several series of experiments were conducted in small scale $20 \mathrm{~kW}$ upstream drop tube reactor presented in Fig. 1. The insulated one meter length cylindrical ceramic combustion chamber (1) has inner diameter $100 \mathrm{~mm}$ and $10 \mathrm{~mm}$ thickness of walls. Flue gases leave combustion chamber (1) through exhaust fan (2). In the bottom part of the chamber there is a low flame gas burner (3). Through the axis of the burner solid fuel dust with transport air (4) (primary air) is supplied into the combustion chamber. The thickness of heat insulation of the chamber (8) made by very thin ceramic fibres is about $150 \mathrm{~mm}$. Gas fuel (5) (propane) is supplied into the burner from the cylinder, then is mixed with secondary air (6) in the mixing chamber of the burner (3) and afterwards through stabilizing cartridge gets the chamber (1) where is ignited. The gas burner (3) generates flue gases at the specific temperature and gas composition to make the ignition of solid fuel possible. By the change of gas (5) or secondary air (6) the temperature of flue gases, excess of air, quantity of supplied heat into the chamber (1) and temperature at the outlet of chamber (9) may be controled and changed during measurements. The solid fuel is supplied through coal dust feeder (10) which enables changing the fuel feed rate and quantity of primary air (7). About one meter from the front of the burner (3) there is a deposit $10 \mathrm{~mm}$ diameter pipe (11) hanged on beams of the extensometer balance (12). Bending the beams as a result of slag deposit causes the resultant voltage which is the function of mass increase of deposit pipe. The temperature of flue gases is measured close to deposit pipe by thermocouple (13).

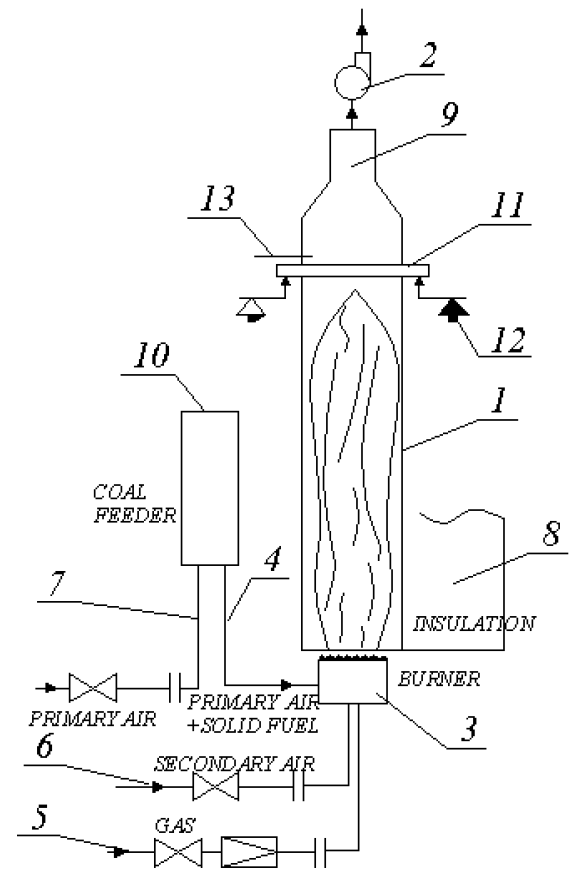

Fig. 1. Scheme of the $20 \mathrm{~kW}$ slagging test fasility

Investigations consist of burning pulverized samples of fuel with quantity about 0.41-0.55 $\mathrm{g} / \mathrm{s}(1.5-2 \mathrm{~kg} / \mathrm{h})$ in heated in advance by gaseous fuel combustion, chamber in suitable, variable during duration of experiments conditions (excess air, temperature). In this way rate of slag deposition for various temperatures and the beginning temperature of slagging is obtained. The gaseous fuel creates the suitable conditions for experiments and is 
continuously used during the whole experiment. The effect of gaseous flame itself for solid fuel combustion is negligible since solid fuel is injected with higher speed into already mixed and hot flue gases similarly as in real scale boilers fuel is injected into the combustion chamber. Higher amount of water from propane combustion is compensated by more predried solid fuel in laboratory conditions as compared to real ones. $\mathrm{T}_{\text {beg }}$ and $\mathrm{k}_{\mathrm{z}}$, which are respectively, beginning temperature of slagging and index of slagging intensity are determined by below formulas:

$$
\begin{aligned}
& B_{z}=\frac{M_{z} \cdot F_{k}}{M_{p} \cdot F_{r}} \\
& B_{z}=e^{k_{z} \cdot\left(\frac{T_{s p}}{T b e g}-1\right)}-1
\end{aligned}
$$

where:

$\mathrm{B}_{\mathrm{z}}$ - relative slagging intensity, $\mathrm{M}_{\mathrm{z}}$ - collected mass of slag on deposition pipe [g],

$\mathrm{M}_{\mathrm{p}}$ - mass of ash flown through the combustion chamber of the slagging test facility [g],

$\mathrm{F}_{\mathrm{k}}$ - area of the cross section of the combustion chamber of the slagging test facility $\left[\mathrm{m}^{2}\right]$,

$\mathrm{F}_{\mathrm{r}}$ - active area of pipe $\left[\mathrm{m}^{2}\right]$,

$\mathrm{T}_{\text {beg }}$ - beginning temperature of slagging $[\mathrm{K}]$,

$\mathrm{k}_{\mathrm{z}}$ - index of slagging intensity

$\mathrm{T}_{\mathrm{sp}}$ - temperature of combustion $[\mathrm{K}]$.

More than 40 different solid fuels and their blends were investigated as hard or lignite coals, raw and torrefied biomasses, saw dusts (SDI - SDIII), sewage sludge (SS) and RDF. Tab. 1 presents technical and ash mineral analysis of investigated fuels and their blends, $\mathrm{T}_{\text {begcal, }}$ Slag-Index and Foul-Index calculated on commonly available formulas [13] and experimentally obtained $k_{z}$ and $T_{\text {beg. }}$. Blends were prepared on mass (SDI, SDII, SDIII, SS, $\mathrm{RDF}$ ) or energy basis (P, B, S, TP, TB, TS). It might been seen from the very beginning that calculated slagging indexers usually do not correspond with experimentally obtained $\mathrm{k}_{\mathrm{z}}$ and $\mathrm{T}_{\text {beg. }}$ This is especially visible in case of $\mathrm{T}_{\text {begcal }}$ which generally does not change markedly over the all fuels (including biomass) with several exceptions keeping the value around $1250 \mathrm{~K}$. The opposite behaviour may be seen in case of $\mathrm{T}_{\text {beg }}$ which changes from 459 to $1301 \mathrm{~K}$. For instance interesting behaviour might be seen in case of hard coal HC1 and raw and torrefied beech (B, TB). HC1 characterized by unusual ash mineral analysis has high $\mathrm{k}_{\mathrm{z}}$ but simultaneously high $\mathrm{T}_{\text {beg. }}$. The opposite situation occurs in case of beech, raw and torrefied. After adding $20 \%$ of TB by energy to this coal $\mathrm{T}_{\text {beg }}$ of this blend decrease markedly. After adding $40 \%$ one will expect further decrease of $\mathrm{T}_{\text {beg }}$ but this is not the point. However $\mathrm{k}_{\mathrm{z}}$ increases for this blend even for pure TB $\mathrm{k}_{\mathrm{z}}$ was not too high and the amount of hard coal (the fuel with higher $\mathrm{k}_{\mathrm{z}}$ ) decreases when adding more TB. 
Table 1. Technical and ash analysis of fuels. Calculated and laboratory obtained slagging indexers

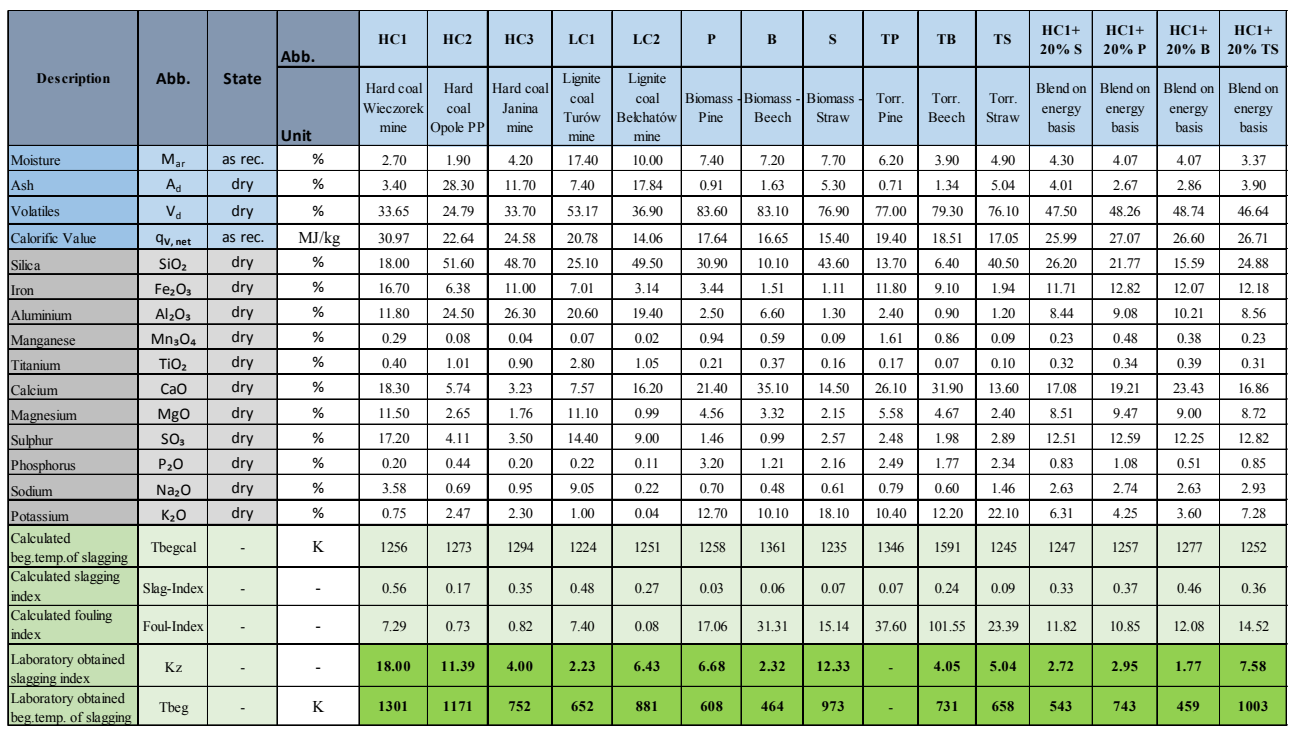

\begin{tabular}{|c|c|c|c|c|c|c|c|c|c|c|c|c|c|c|c|c|c|c|c|}
\hline & & & Abb. & \begin{tabular}{|c|}
$\mathrm{HC1}+$ \\
$40 \% \mathrm{TS}$
\end{tabular} & $\begin{array}{c}\text { HC1+ } \\
20 \% \text { TP }\end{array}$ & \begin{tabular}{c|} 
HC1+ \\
$40 \% \mathrm{TP}$ \\
\end{tabular} & $\begin{array}{c}\text { HC1+ } \\
20 \% \text { TB }\end{array}$ & $\begin{array}{c}\mathrm{HC} 1+40 \\
\% \mathrm{~TB}\end{array}$ & $\begin{array}{c}\text { HC3+ } \\
20 \% \text { S }\end{array}$ & \begin{tabular}{c|} 
LC1+ \\
$20 \%$ S
\end{tabular} & $\begin{array}{l}\mathrm{LC} 1+ \\
20 \% \mathrm{P}\end{array}$ & $\begin{array}{c}\text { LCI+ } \\
20 \% \text { TP }\end{array}$ & $\begin{array}{c}\text { LC1+ } \\
20 \% \text { TB }\end{array}$ & $\begin{array}{c}\text { LC2+ } \\
20 \% \mathrm{TS}\end{array}$ & \begin{tabular}{|c|} 
LC2+ \\
$20 \%$ \\
TB \\
\end{tabular} & LC3 & LC4 & LC5 & LC6 \\
\hline Description & Abb. & State & Unit & $\begin{array}{c}\text { Blend on } \\
\text { energy } \\
\text { basis }\end{array}$ & $\begin{array}{c}\text { Blend on } \\
\text { energy } \\
\text { basis }\end{array}$ & $\begin{array}{c}\text { Blend on } \\
\text { energy } \\
\text { basis }\end{array}$ & $\begin{array}{c}\text { Blend on } \\
\text { energy } \\
\text { basis }\end{array}$ & $\begin{array}{c}\text { Blend on } \\
\text { energy } \\
\text { basis }\end{array}$ & $\begin{array}{c}\text { Blend on } \\
\text { energy } \\
\text { basis }\end{array}$ & $\begin{array}{c}\text { Blend on } \\
\text { energy } \\
\text { basis }\end{array}$ & $\begin{array}{c}\text { Blend on } \\
\text { energy } \\
\text { basis }\end{array}$ & $\begin{array}{c}\text { Blend on } \\
\text { energy } \\
\text { basis }\end{array}$ & $\begin{array}{c}\text { Blend on } \\
\text { energy } \\
\text { basis }\end{array}$ & $\begin{array}{c}\text { Blend on } \\
\text { energy } \\
\text { basis }\end{array}$ & $\begin{array}{c}\text { Blend on } \\
\text { energy } \\
\text { basis }\end{array}$ & \begin{tabular}{|c|c|} 
Lignite \\
coal \\
Jóźzin \\
mine
\end{tabular} & \begin{tabular}{|c|} 
Lignite \\
coal \\
Drzewce \\
mine
\end{tabular} & \begin{tabular}{|c|} 
Lignite \\
coal \\
Kazimierz \\
mine
\end{tabular} & \begin{tabular}{|c} 
Lignite \\
coal \\
Lubstów \\
mine \\
\end{tabular} \\
\hline \begin{tabular}{|l} 
Moisture \\
\end{tabular} & $M_{a r}$ & as rec. & $\%$ & 3.89 & 3.65 & 4.44 & 3.03 & 3.31 & 5.13 & 15.12 & 15.27 & 15.21 & 14.70 & 9.17 & 9.12 & 12.00 & 4.10 & 11.90 & 4.30 \\
\hline \begin{tabular}{|l} 
Ash \\
\end{tabular} & $A_{d}$ & dry & $\%$ & 4.29 & 2.67 & 2.06 & 2.83 & 2.36 & 9.99 & 6.91 & 6.02 & 6.09 & 6.19 & 15.75 & 15.46 & 10.60 & 25.90 & 12.50 & 8.40 \\
\hline Volatiles & $v_{d}$ & dry & $\%$ & 56.59 & 45.40 & 55.24 & 46.26 & 56.67 & 45.23 & 58.75 & 59.64 & 57.82 & 58.40 & 43.29 & 43.02 & 47.00 & 40.60 & 45.00 & 47.30 \\
\hline Iron & $\mathrm{Fe}_{2} \mathrm{O}_{3}$ & dry & $\%$ & 8.73 & 15.37 & 14.26 & 14.60 & 12.86 & 8.36 & 5.62 & 6.25 & 7.95 & 7.43 & 2.94 & 4.00 & 12.00 & 5.26 & 6.31 & 8.29 \\
\hline \begin{tabular}{|l} 
Aluminium \\
\end{tabular} & $\mathrm{Al}_{2} \mathrm{O}_{3}$ & dry & $\%$ & 6.07 & 9.25 & 7.12 & 8.79 & 6.30 & 19.63 & 16.06 & 16.75 & 17.04 & 16.66 & 16.43 & 16.73 & 1.69 & 1.09 & 2.28 & 3.72 \\
\hline \begin{tabular}{|l|} 
Manganese \\
\end{tabular} & $\mathrm{Mn}_{3} \mathrm{O}_{4}$ & dry & $\%$ & 0.18 & 0.65 & 0.95 & 0.45 & 0.58 & 0.05 & 0.07 & 0.26 & 0.37 & 0.23 & 0.03 & 0.14 & 0.52 & 0.11 & 0.43 & 0.36 \\
\hline Titanium & $\mathrm{TiO}_{2}$ & dry & $\%$ & 0.24 & 0.34 & 0.29 & 0.31 & 0.23 & 0.70 & 2.18 & 2.25 & 2.29 & 2.25 & 0.90 & 0.91 & 0.21 & 0.28 & 0.22 & 0.42 \\
\hline \begin{tabular}{|l|} 
Calcium \\
\end{tabular} & $\mathrm{CaO}$ & dry & $\%$ & 15.76 & 20.41 & 22.18 & 22.06 & 25.16 & 6.24 & 9.20 & 10.51 & 11.19 & 12.44 & 15.78 & 18.47 & 27.50 & 11.30 & 27.10 & 43.90 \\
\hline \begin{tabular}{|l|} 
Magnesium \\
\end{tabular} & $\mathrm{MgO}$ & dry & $\%$ & 6.58 & 9.89 & 8.55 & 9.61 & 8.05 & 1.86 & 8.99 & 9.71 & 10.02 & 9.81 & 1.22 & 1.52 & 5.20 & 1.13 & 5.23 & 4.02 \\
\hline \begin{tabular}{|l|}
$\begin{array}{l}\text { Calculated slagging } \\
\text { index }\end{array}$ \\
\end{tabular} & Slag-Index & - & - & 0.25 & 0.48 & 0.40 & 0.55 & 0.52 & 0.36 & 0.39 & 0.42 & 0.49 & 0.53 & 0.29 & 0.33 & 12.94 & 0.25 & 3.58 & 2.04 \\
\hline \begin{tabular}{|l|}
$\begin{array}{l}\text { Calculated fouling } \\
\text { index }\end{array}$ \\
\end{tabular} & Foul-Index & - & - & 18.48 & 12.15 & 17.56 & 14.78 & 25.18 & 50 & 9.10 & 34 & 9.60 & 10.60 & 1.49 & 0.89 & 1.68 & 0.02 & 0.32 & 0.67 \\
\hline $\begin{array}{l}\text { Laboratory obtained } \\
\text { slagging index }\end{array}$ & $\mathrm{Kz}$ & - & - & 4.03 & 16.15 & 9.61 & 4.04 & 14.02 & 6.96 & 9.17 & 11.59 & 9.03 & 4.70 & 12.88 & 9.20 & 7.12 & 7.84 & 7.97 & 8.37 \\
\hline $\begin{array}{l}\text { Laboratory obtained } \\
\text { beg.temp. of slagging }\end{array}$ & Tbeg & . & K & 710 & 1098 & 1017 & 836 & 1136 & 1038 & 1083 & 1120 & 1057 & 896 & 1044 & 1075 & 896 & 1063 & 1006 & 1056 \\
\hline
\end{tabular}




\begin{tabular}{|c|c|c|c|c|c|c|c|c|c|c|c|c|c|c|c|c|c|}
\hline \multirow[b]{2}{*}{ Abb. } & \multirow[b]{2}{*}{ State } & \multirow[t]{2}{*}{ Abb. } & \multirow{2}{*}{\begin{tabular}{|c|} 
HC4 \\
$\begin{array}{c}\text { Hard } \\
\text { coal from } \\
\text { RPA }\end{array}$ \\
\end{tabular}} & \multirow{2}{*}{\begin{tabular}{|c|}
$\begin{array}{c}\text { HC4+ } \\
5 \% \text { SS }\end{array}$ \\
$\begin{array}{c}\text { Blend } \\
\text { on mass } \\
\text { basis }\end{array}$ \\
\end{tabular}} & \multirow{2}{*}{\begin{tabular}{|c|} 
HC4+ \\
$10 \%$ SS \\
$\begin{array}{c}\text { Blend on } \\
\text { mass } \\
\text { basis }\end{array}$ \\
\end{tabular}} & \multirow{2}{*}{\begin{tabular}{|c|} 
HC4+ \\
$15 \%$ SS \\
$\begin{array}{c}\text { Blend on } \\
\text { mass } \\
\text { basis }\end{array}$ \\
\end{tabular}} & \multirow{2}{*}{\begin{tabular}{|c|} 
HC4+ \\
$20 \%$ SS \\
$\begin{array}{c}\text { Blend on } \\
\text { mass } \\
\text { basis }\end{array}$ \\
\end{tabular}} & \multirow{2}{*}{\begin{tabular}{|c|}
$\begin{array}{c}\text { HC4+ } \\
\mathbf{\%} \text { SDI }\end{array}$ \\
$\begin{array}{c}\text { Blend on } \\
\text { mass } \\
\text { basis }\end{array}$ \\
\end{tabular}} & \multirow{2}{*}{ 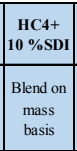 } & \multirow{2}{*}{\begin{tabular}{|c|} 
HC4+ \\
$15 \% \mathrm{SDI}$ \\
$\begin{array}{c}\text { Blend on } \\
\text { mass } \\
\text { basis }\end{array}$ \\
\end{tabular}} & \multirow{2}{*}{\begin{tabular}{|c|} 
HC4 + \\
$20 \%$ SDI \\
Blend on \\
mass basis
\end{tabular}} & \multirow{2}{*}{\begin{tabular}{|c|}
$\begin{array}{c}\text { HC4 }+ \\
10 \\
\% \text { RDF }\end{array}$ \\
Blend on \\
mass basis \\
\end{tabular}} & \multirow{2}{*}{\begin{tabular}{|c|}
$\begin{array}{c}\text { HC4 }+ \\
\mathbf{2 0} \\
\text { \%RDF }\end{array}$ \\
Blend on \\
mass basis
\end{tabular}} & \multirow{2}{*}{\begin{tabular}{|c|} 
HC5 \\
Hard coal \\
Dolna \\
Odra PP
\end{tabular}} & \multirow{2}{*}{\begin{tabular}{|c|} 
HC5+ \\
$14 \%$ SDII \\
Blend on \\
mass basis
\end{tabular}} & \multirow{2}{*}{\begin{tabular}{|c|} 
HC6 \\
Harc coal \\
Stalowa \\
Wola PP \\
\end{tabular}} & \multirow{2}{*}{\begin{tabular}{|c|}
$\begin{array}{c}\text { HC6+ } \\
5 \% \text { SDIII }\end{array}$ \\
$\begin{array}{c}\text { Blend on } \\
\text { mass basis }\end{array}$ \\
\end{tabular}} \\
\hline & & & & & & & & & & & & & & & & & \\
\hline$M_{\mathrm{ar}}$ & as rec. & $\%$ & 4.40 & 4.83 & 5.40 & 5.43 & 5.60 & 4.63 & 4.70 & 5.30 & 5.90 & 4.00 & 3.90 & 1.70 & 2.50 & 2.30 & 2.10 \\
\hline$A_{d}$ & dry & $\%$ & 10.40 & 9.36 & 8.10 & 7.71 & 7.10 & 12.43 & 14.70 & 16.15 & 17.60 & 11.10 & 11.10 & 22.60 & 21.60 & 25.20 & 27.30 \\
\hline $\mathrm{SiO}_{2}$ & dry & $\%$ & 38.10 & 34.20 & 30.30 & 29.50 & 28.70 & 37.85 & 37.60 & 37.40 & 37.20 & 35.50 & 34.30 & 50.00 & 50.60 & 53.14 & 57.50 \\
\hline $\mathrm{Fe}_{2} \mathrm{O}_{3}$ & dry & $\%$ & 6.10 & 8.30 & 10.50 & 11.05 & 11.60 & 5.85 & 5.60 & 5.45 & 5.30 & 5.65 & 5.44 & 6.44 & 6.35 & 9.51 & 6.00 \\
\hline $\mathrm{Al}_{2} \mathrm{O}_{3}$ & dry & $\%$ & 28.70 & 24.95 & 21.20 & 19.95 & 18.70 & 28.75 & 28.80 & 27.80 & 26.80 & 24.00 & 23.70 & 27.40 & 26.50 & 18.90 & 24.03 \\
\hline $\mathrm{Mn}_{3} \mathrm{O}_{4}$ & dry & $\%$ & 0.13 & 0.14 & 0.15 & 0.16 & 0.17 & 0.15 & 0.17 & 0.19 & 0.21 & 0.12 & 0.12 & 0.08 & 0.09 & 0.17 & 0.06 \\
\hline $\mathrm{TiO}_{2}$ & dry & $\%$ & 1.46 & 1.27 & 1.07 & 1.02 & 0.96 & 1.43 & 1.40 & 1.38 & 1.35 & 1.73 & 1.98 & 1.08 & 1.08 & 0.86 & 1.29 \\
\hline $\mathrm{Na}_{2} \mathrm{O}$ & dry & $\%$ & 0.54 & 0.50 & 0.46 & 0.52 & 0.57 & 0.58 & 0.61 & 0.68 & 0.74 & 0.69 & 0.63 & 1.03 & 1.00 & 0.80 & 0.67 \\
\hline $\mathrm{K}_{2} \mathrm{O}$ & dry & $\%$ & 0.65 & 0.78 & 0.91 & 1.02 & 1.13 & 0.90 & 1.15 & 1.26 & 1.36 & 0.73 & 0.47 & 3.12 & 3.14 & 2.18 & 2.54 \\
\hline Tbegcal & - & K & 1252 & 1247 & 1243 & 1242 & 1241 & 1251 & 1250 & 1249 & 1247 & 1245 & 1242 & 1282 & 1278 & 1264 & 1308 \\
\hline Slag-Index & - & - & 0.55 & 0.32 & 0.37 & 0.36 & 0.35 & 0.32 & 0.34 & 0.36 & 0.38 & 0.35 & 0.35 & 0.16 & 0.16 & 0.22 & 0.11 \\
\hline Foul-Index & - & - & 0.40 & 0.54 & 0.72 & 0.86 & 1.02 & 0.50 & 0.59 & 0.67 & 0.76 & 0.56 & 0.47 & 0.88 & 0.90 & 0.92 & 0.53 \\
\hline $\mathrm{Kz}$ & - & - & 11.89 & 9.65 & 7.61 & 9.62 & 9.64 & 4.97 & 5.34 & 5.38 & 5.56 & 6.77 & 7.81 & 6.97 & 6.35 & 9.85 & 13.86 \\
\hline Tbeg & - & K & 1163 & 1096 & 1013 & 1123 & 1191 & 982 & 987 & 992 & 991 & 1034 & 1028 & 1060 & 1020 & 1100 & 1220 \\
\hline
\end{tabular}

This proves that slagging properties of fuel blends are sometimes not additive as one could expect on the basis of $\mathrm{T}_{\text {begcal }}$, slag and fouling indexers determined on the basis of ash mineral analysis. Nevertheless this is not the topic of this paper to be discussed further.

\section{ANN simulations}

Principal component analysis (PCA) is a well-known, widely used statistical technique. In pattern recognition, $\mathrm{PCA}$ is used in various forms for optimal feature extraction and data compression. In general PCA finds an orthogonal set of directions in the input space and provides a way of finding the projections into these directions in an ordered fashion. The first principal component is the one that has the largest projection (the projection is the shadow of the data cluster in each direction). The orthogonal directions are called the eigenvectors of the correlation matrix of the input vector, and the projections the corresponding eigenvalues. Since PCA orders the projections, the dimensionality can be reduced by truncating the projections to a given order. PCA is normally done by analytically solving an eigenvalue problem of the input correlation function. However, Sanger and Oja $[14,15]$ demonstrated that PCA can be accomplished by a single layer linear neural network (Fig. 2) trained with a modified Hebbian learning rule. Oja's rule was find by one of the author to be more attractive than Sangers for this application [16]. 


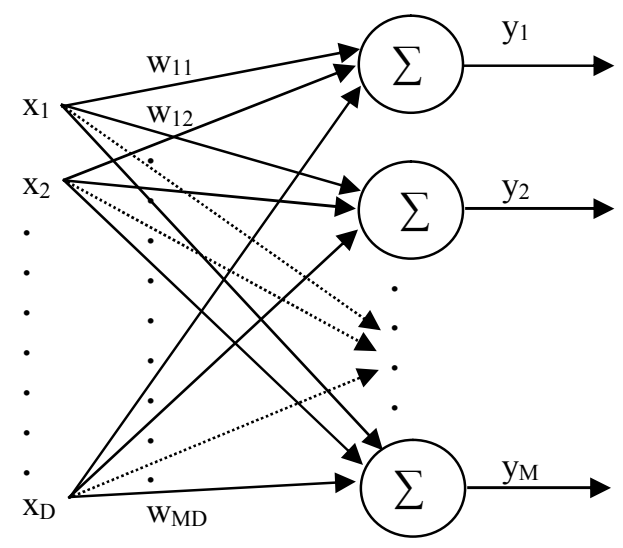

Fig. 2. A PCA network to project the data from $\mathrm{D}$ to $\mathrm{M}$ dimensions ( $\mathrm{x}$ - inputs, $\mathrm{w}$-weights, $\mathrm{y}$ outputs)

What is interesting in the PCA network is computing the eigenvectors of the correlation function of the input without ever computing the correlation function. Sanger showed that this learning procedure converges to the correct solution, i.e. the weights of the PCA network approach the first $\mathrm{m}$ principal components of the input data matrix. The outputs are therefore related to the eigenvalues and can be used as input to another neural network. Thus PCA can be used for data reduction in conjunction with MFNN. The importance of PCA analysis is that the number of inputs for the MFNN can be significantly reduced, which positively impacts the number of required training patterns and the training time as well.

Authors proposed PCA-MFNN hybrid network with one hidden layer with statistical analysis of outputs which classifies which results are acceptable on the basis of averages and standard deviations of trained and tested twenty neural networks. Main investigated elements in ANN were : principal components number (PC) ranging from 3 to 8 , hidden neurons $(\mathrm{HN})$ number ranging from 6 to 10 and multiply of training patterns by random duplication of existing training data. Levenverg-Marquard training algorithm was used to train supervisied part of network - MFNN, whilst for unsupervised - PCA, Oja's rule. In MFNN tangh activation function was used both in hidden and output layer. 15 inputs were defiened : four parameters from technical analysis of fuel and eleven from ash mineral chemical analysis as presented in Table 1.38 sets of data were choosen for training while 8 for testing.

\section{Results and discussion}

Figures 3-6 present the results of MFNN and PCA-MFNN simulations. Graphs presents training results, average testing results and the best test results. In case of MFNN no satisfactory results were obtained. In that case also training process was unstable, very often not reaching intended threshold. In case of hybrid PCA-MFNN for 3-4 PC elements similar behaviour was observed during training however testing results were more promising. Best results were obtained for $\mathrm{PC}$ ranging from 5-8. Further increase of PC does not decrease the test error and starts to increase training time. It might be seen that for some testing sets no satisfactory results were obtained. This might be caused by e.g. not enough training data sets or not proper training data sets selection for training. Presented test results are averages from 20 ANN. Results with too high standard deviations are signed as too uncertain. This is 
especially important in final real scale application in Common Intelligent Boiler Operation Platform (CIBOP).
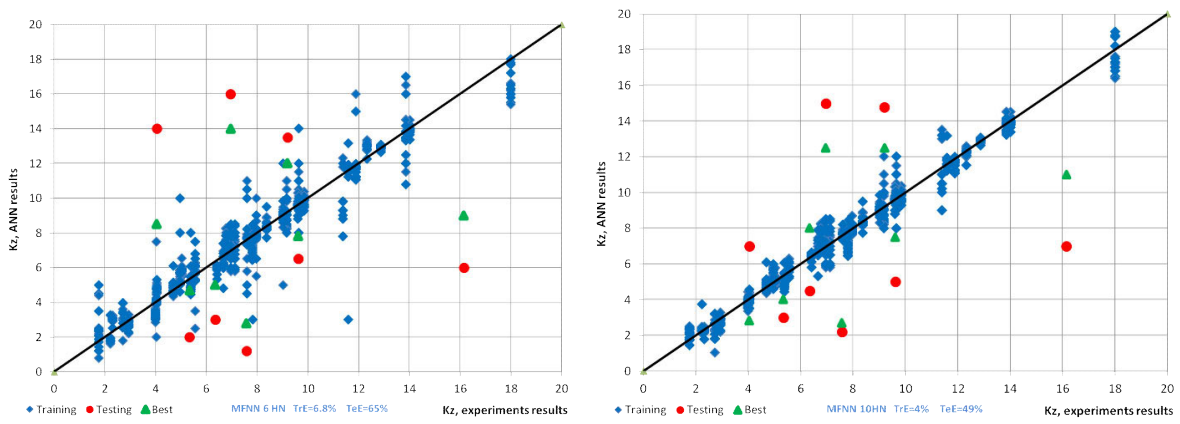

Fig. 3. MFNN simulation results for $\mathrm{k}_{\mathrm{z}}$ predicting for 6 and 10 hidden neurons
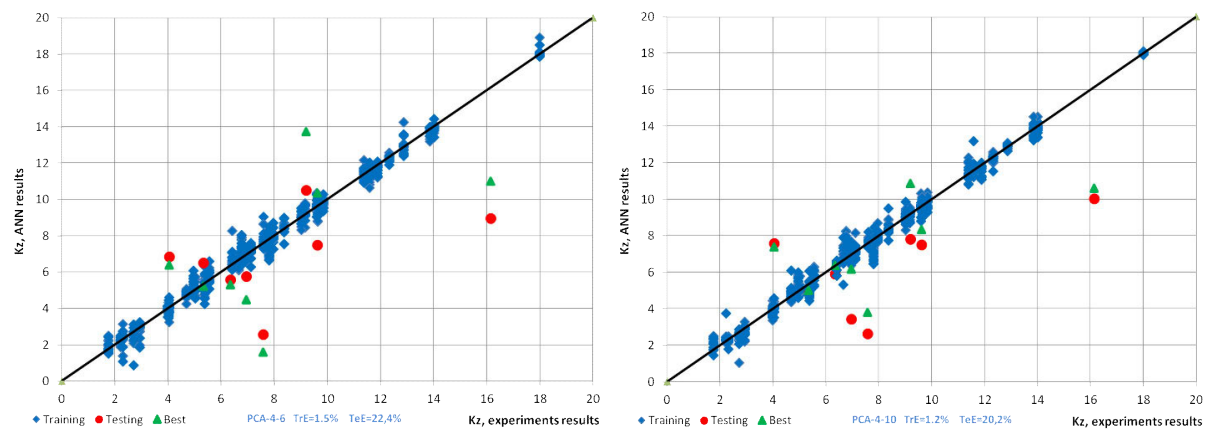

Fig. 4. PCA simulation results for $\mathrm{k}_{z}$ predicting for $4 \mathrm{PC}$ elements and 6 or 10 hidden neurons
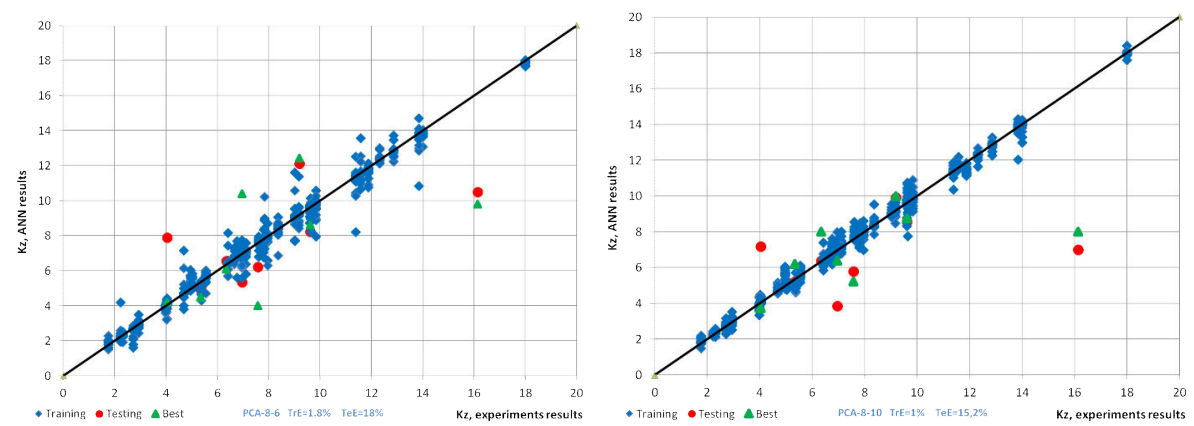

Fig. 5. PCA simulation results for $\mathrm{k}_{\mathrm{z}}$ predicting for $8 \mathrm{PC}$ elements and 6 or 10 hidden neurons 

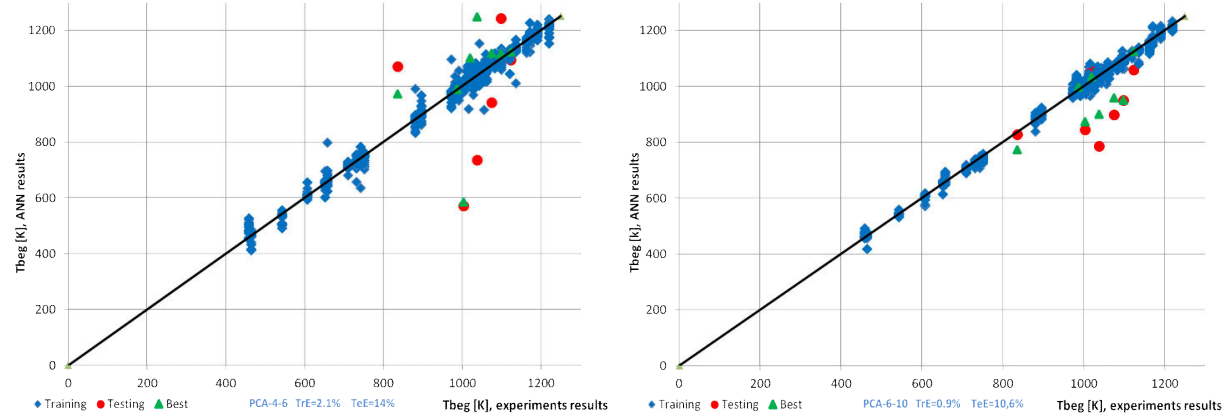

Fig. 6. PCA simulation results for $\mathrm{T}_{\text {beg }}$ predicting for $8 \mathrm{PC}$ elements and 6 or 10 hidden neurons

Figure 7 presents the linear and average PCA-MFNN sensisivity analysis [17] of more important ash components (inputs to $A N N$ ) with $\mathrm{k}_{\mathrm{z}}$ and $\mathrm{T}_{\text {beg }}$ (outputs from $\mathrm{ANN}$ ). In general there is no linear corelations of searched parameters with ash mineral analysis. Maximum values of linear correlation coefficient can be found for silica, pottasium, aluminium and titanium in relation to $\mathrm{T}_{\text {beg }}$ which seems to be "more realistic" parameter compared to $\mathrm{k}_{\mathrm{z}}$ intensity. In case of PCA-MFNN sensisivity for $\mathrm{T}_{\text {beg }}$ and $\mathrm{k}_{\mathrm{z}}$ covers each other and reach maximum for phosphorus and potassium. However other parameters of ash are also important in PCA-MFNN performance. Figure 8 highligts the sensivity behaviour for $\mathrm{k}_{\mathrm{z}}$ and $\mathrm{T}_{\text {beg }}$ for different number of PC elements (for 8 hidden neurons). In case of $\mathrm{T}_{\text {beg }}$ increasing the number of PC usually increases or decreases the importance of given ash mineral parameter. In case of $\mathrm{k}_{\mathrm{z}}$ this behaviour can not be classified in such manner rather.
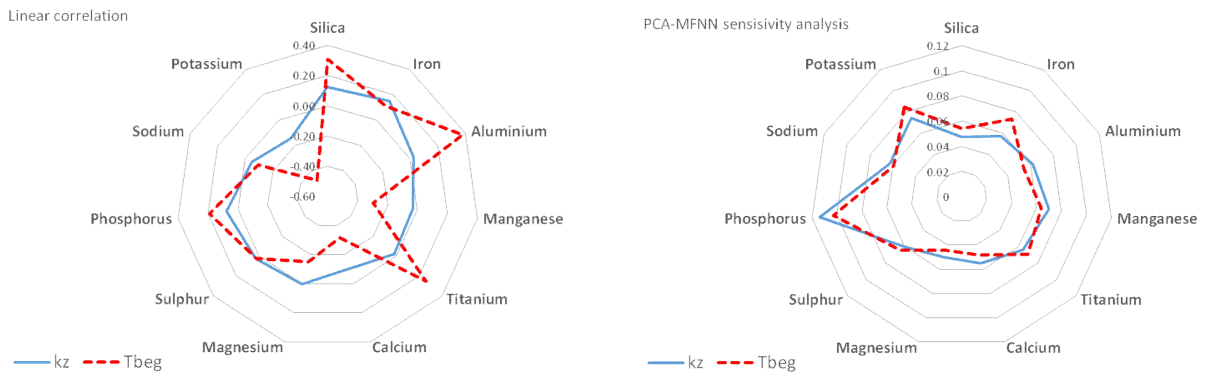

Fig. 7. Linear correlation and PCA-MFNN sensivity analysis between inputs and outputs of ANN
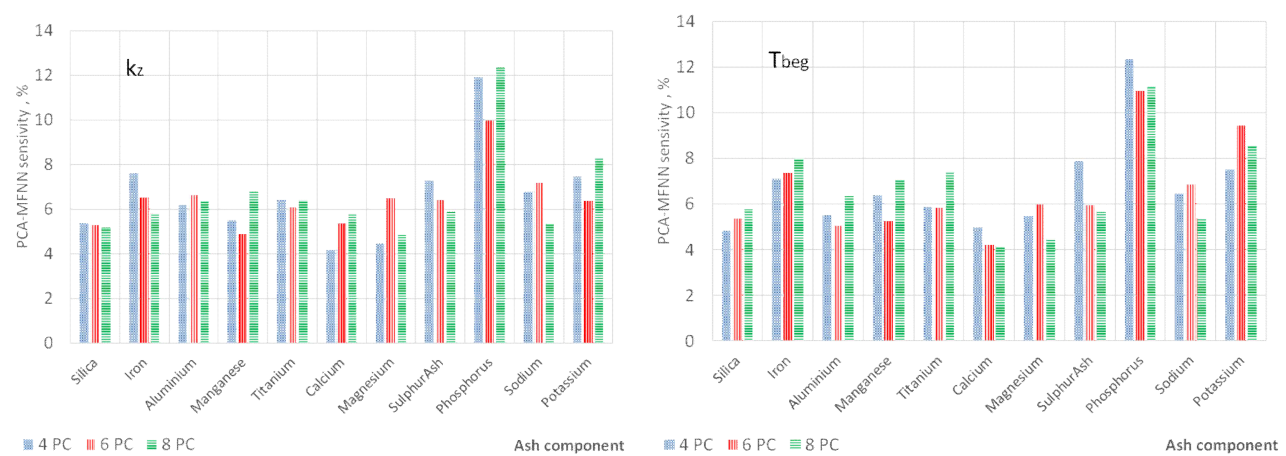

Fig. 8. Sensisivity (importance) for different number of $\mathrm{PC}$ elements for $\mathrm{k}_{\mathrm{z}}$ and $\mathrm{T}_{\mathrm{beg}}$ 


\section{Conclusions}

Reasonable predictions of index of slagging intensity $\left(\mathrm{k}_{\mathrm{z}}\right)$ and beginning temperature of slagging $\left(\mathrm{T}_{\text {beg }}\right)$ were obtained for PCA-MFNN hybrid network with statistical analysis of output data. It was found that more than 4 PC elements and Oja's rule instead of Sanger's rule should be applied. There are still some predictions errors especially for slagging intensity $\mathrm{k}_{\mathrm{z}}$ which are too high or the results have too high standard deviations. Duplication of existing training data sets does not have visible effect for ANN performance.

The ANN model needs further improvement by enlarging the training database and better selection methods of training data to be used in training process. After further improvements neural network model will be used in Common Intelligent Boiler Operation Platform (CIBOP) being elaborated within CERUBIS research project for two BP-1150 and BB-1150 steam boilers.

The authors would like to acknowledge the European Commision for financial support under the European Fifth Framework Programme for Energy, Environment and Sustainable Development Programme and Research Fund for Coal and Steel, and Polish Ministry of Science and Higher Education fo co-financing of intenational projects (PowerFlam2 project Nne5-2001-00907, Cerubis project RFCR-CT-2014-00008).

\section{References}

1. J.A. Rundygina, Nauczne Trudy, Moscow (1983)

2. J. Żelkowski, A. Sturm. O. Mauritz, VGB Power-Tech, 10 (1998)

3. T. Heinzel, V. Siegle, H. Spliethoff, K.R.G. Hein, Fuel Proces. Techn., 54, 109-125 (1998)

4. R.P. Gupta, T.F. Wall, I. Kajigaya, S. Miyame, Y. Tsumita, Prog. Energ. Comb. Sc., 24, 523-543 (1998)

5. Y. Liu, R. Gupta, A. Sharma, T. Wall, A. Butcher, G. Miller, P. Gottlieb, D. French, Fuel, 84, 1259-1267 (2005)

6. L.Y. Huang, J.S. Norman, M. Pourkashanian, A. Williams, Fuel, 75, 271-279 (1996)

7. C. Zheng, G. Liu, Y. Huang, Chem. Eng. Min. Proces., 10, 61-75 (2002)

8. C. Yin, Z.Y. Luo, M.J. Ni, K.F. Cen, Fuel, 77, 1777-1782 (1998)

9. H. Salehfar, S.A. Benson, Neurocom., 23, 195-206 (1998)

10. E. Teruel, C. Cortes, L.I. Diez, I. Arauzo, Chem. Engine. Sc., 60, 5035-5048 (2005)

11. Y.P. Liu, M.G. Wu, J.X. Qian, Thermoch. Acta, 454, 64-68, (2007)

12. J. Qian, X. Jiang, F. Wang, Y. Chi, J. Yan, Thermoch. Acta, 526, 29-34, (2011)

13. M. Pronobis, Modernizacja kotłów energetycznych (2000)

14. T. Sanger, Neural Networks, 12, 459-473 (1989)

15. E. Oja, Jour. Mathem. Biol., 15, 239-245 (1982)

16. S. Kakietek, W. Rybak, Proc. from AI-21 Conf., Siedlce, Poland (2006)

17. T. Tchaban, M.J. Taylor, J.P. Griffin, Neur. Comp. and Appl., 7, 309-317 (1998) 